\title{
Detection of Trace Metal Contamination Around a Dumpsite in Iyara Area Warri Nigeria Using Geoelectrical and Geochemical Methods
}

\author{
Merrious O. Ofomola ${ }^{1 *}$, Anita Franklin Akpolile ${ }^{1}$, Ochuko Anomohanran ${ }^{1}$, Taiye O. Adeoye ${ }^{2}$, Musa A. Bawallah ${ }^{3}$ \\ ${ }^{1}$ Department of Physics, Delta State University, Abraka 330105, Nigeria \\ ${ }^{2}$ Department of Geophysics, University of Ilorin, Ilorin 240103, Nigeria \\ ${ }^{3}$ Department of Applied Geophysics, Federal University of Technology, Akure 240252, Nigeria
}

Corresponding Author Email: ovirimerrious@yahoo.com

https://doi.org/10.18280/eesrj.080303

Received: 4 September 2021

Accepted: 20 September 2021

\section{Keywords:}

contaminated soil, enrichment factor, multiple pollution index, resistivity, toxicity

\begin{abstract}
Trace metal concentration in soils of Iyara area of Warri, Delta State was studied using geophysical and geochemical techniques. Eight vertical electrical sounding (VES) using SAS 1000 Terrameter with maximum current electrode spread of $150 \mathrm{~m}$ in the Schlumberger configuration was carried out. The geoelectric layers obtained are topsoil, clay, sand and fine-medium grained sand. The fine to medium grained sand of the third and fourth layers mainly constitute the aquifer with a depth ranging from $4.8-11.0 \mathrm{~m}$. Soil samples were collected at three of the VES stations covering the dumpsite and stations away from the dumpsite. The trace metal content was higher than the maximum allowable levels in soils as specified by the World Health Organisation (WHO) and Department of Petroleum Resources of Nigeria (DPR) except for $\mathrm{Pb}$ with undetected concentration in VES 3, Mn with $135 \mathrm{mg} / \mathrm{kg}$ in VES 1 and undetected in VES 3 and VES 7. The Multiple pollution index, Enrichment factor, and Non-carcinogenic hazard decreases with increasing distance from the dumpsite. The soil around the dumpsite has been impacted and the results of this study will serve as background information for soil studies and groundwater development in the area.
\end{abstract}

\section{INTRODUCTION}

Industrial pollution has been and continues to be a major cause of environmental degradation. Several studies have previously established that areas very close to industrial activities are characterized by contamination that are obviously noticed in the air, soil, and water [1]. Hence, such activity can have adverse effect on the air, water, and soil, and these can automatically lead to illness and pose great danger to the inhabitants in the affected area. Activities of many industries release various substances that are toxic, including heavy metals to the environment. In most environmental studies, heavy metals are primary markers because they can be identified effectively. This is also because most other organic pollutants may be broken down to harmful constituents and this not the case for metals. Inspite of the remediation, the consequential effect on pollution in the immediate environment may be huge and protracted. However, trace metals that are used as reliable markers for environmental pollution studies include Lead, Cadmium, Copper, Manganese and other selected representative metals. This is because of their high persistence of toxicity and nondegradable conditions in the environment, they are therefore considered severe environmental pollutants [2].

Heavy metals refer to organic waste from petrochemical and other activities [3]. The levels of trace metals in the environment increase when released from rocks. This release can occur through natural processes or through human activities (antropogenic). Natural processes include; the breaking down of solid rocks, expansion of mid-ocean ridges, and volcanic phenomena. The geochemical analysis is normally used in identifying the heavy metals concentration regarded as pollutants and sometimes toxins in water samples either from the surface, borehole, or extracted from soils [4]. As a result of their nondegradable nature and extended biological half-life, heavy metals as well as trace elements are a matter of concern for environmental studies. The most significant parameters controlling the building up of these heavy metals in soils include the organic matter and $\mathrm{pH}$. Metals such as $\mathrm{Cd}$ and $\mathrm{Cu}$ are cumulative poisonous. These metals are capable of causing environmental hazards and are reported to be remarkably toxic. For example, Jegede et al. [5] detected trace metals in vegetable grown soil using electrical resistivity tomography and Instrumental Neutron Activation Analysis (INAA) techniques in Tundawada area of Zaria. Cadmium (Cd) and Chromium (Cr) were detected among metals contaminating the soil and discovered that vegetables grown on that soil were highly vulnerable to contamination by the trace metals due to the leachate plume migration from the dumpsite. Through the inhalation of dust and direct ingestion of soils, heavy metals may find their way into the human body. Laboratory measurements has to be carried out on soils and water samples, taken from nearby streams and boreholes drilled near the site. These kinds of water have to be investigated in order to establish the degree of lateral and horizontal pollutant movement into the surrounding areas [6]. Additional survey, however, has to be carried out by employing selected geophysical method especially the electrical resistivity techniques to ascertain the extent of pollution [7] where the movement of current in the soil is 
affected by the existence of ions dissolved from the waste that move around soil [8]. Hence geophysical characteristics help to easily map the effect of pollutants especially in the boundary demarcation between contaminated and uncontaminated zones [9]. This study therefore unravels the presence of trace metals contamination around the dumpsite using geoelectrical and geochemical methods. This is done by determining layer resistivity and thickness as well as aquifer depth using geoelectrical method and estimating the concentration of heavy metals present in selected areas within the dumpsite using the geochemical method.

\section{LOCATION AND GEOLOGY OF THE STUDY AREA}

The study area, Iyara, is located in Delta State, Nigeria and lies within the coordinates of $5^{\circ} 32^{\prime} 39.2280^{\prime \prime} \mathrm{N}$ and $5^{\circ} 45^{\prime}$ 36.9684" E, an elevation of $8.5 \mathrm{~m}$ above sea level and covers an area of about $2,720 \mathrm{~m}^{2}$ (Figure 1). A major dumpsite in Warri and environs is situated at Iyara where all residents of the vicinity release various types of wastes including hospital wastes, kitchen wastes, poultry wastes, saw-mill wastes, wastes from mechanic workshops, and wastes from various small and large scale industries using various chemicals. Not far from this site are farmlands where various food crops are grown. Some river networks also crisscross the area. Residential houses are not far from this dumpsite with boreholes and hand-dug well as their sources of water for various uses.

\section{METHOD OF STUDY}

In this study, the vertical electrical sounding, employing the Schlumberger array was used. The ABEM SAS 1000 Terrameter introduces direct current to the ground through a pair of current electrodes $(A$ and $B)$, and the corresponding potential difference generated was measured through another pair of potential electrodes $(M$ and $N)$. The choice of minimum electrode separation was based on the target depth of contaminated subsurface [10]. The product of the apparent resistance, $R_{\mathrm{a}}$ of the penetrated earth materials and the geometric factor, $G$ gives the apparent resistivity of the geologic layer and is given by the expression in Eq. (1) [11].

$$
\rho_{a}=\pi R_{a} \frac{\left\{\left(\frac{A B}{2}\right)^{2}-\left(\frac{M N}{2}\right)^{2}\right\}}{M N}
$$

and the geometric factor given as Eq. (2).

$$
G=\pi \frac{\left\{\left(\frac{A B}{2}\right)^{2}-\left(\frac{M N}{2}\right)^{2}\right\}}{M N}
$$

Eight VES sample points were occupied (Figure 2) and the data obtained from the electrical resistivity survey were plotted on a log-log graph paper manually with electrode separation $(\mathrm{AB} / 2)$ on the abscissa and apparent resistivity value on the ordinate. The partial curve matching using twolayer standard master curve and the related auxiliary curves were used to obtain the initial value of the resistivity and thickness of the subsurface layers. The data obtained were interpreted qualitatively by curve matching, and quantitatively and qualitatively by comparing the curve obtained with standard curves to calculate layer resistivity and thickness. The geochemical analysis involves the collection soil samples with a hand auger at the vicinity of the dumpsite and distance away from it (Figure 2). At each location, samples were collected at $1 \mathrm{~m}$ depth. The soil samples were air-dried and sieved to pass through $2 \mathrm{~mm}$ mesh sieve and analysis were done at The Central Laboratory, University of Ibadan, Nigeria to determine the concentration of metals. The following indices were determined.

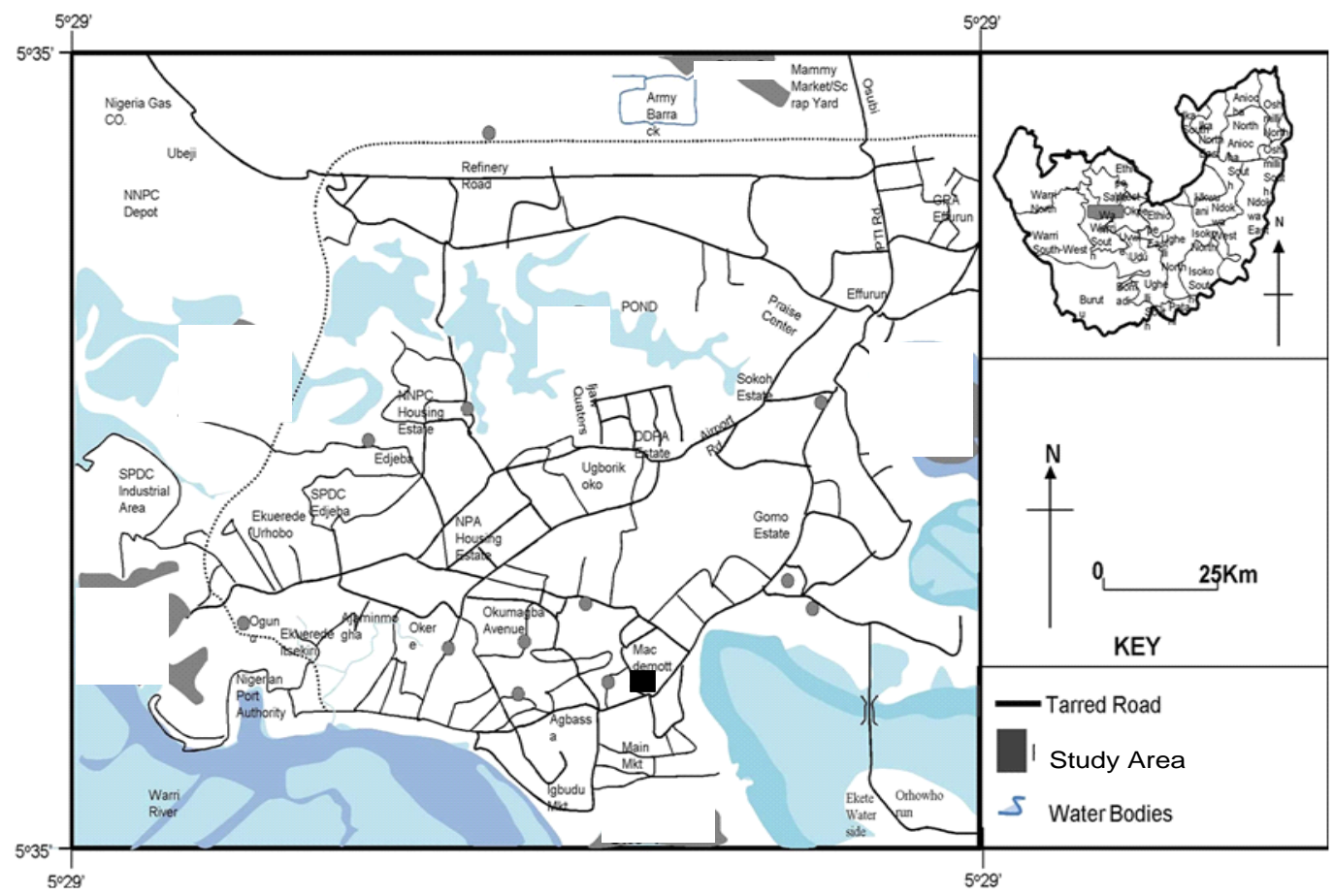

Figure 1. Map of Warri showing the study location 


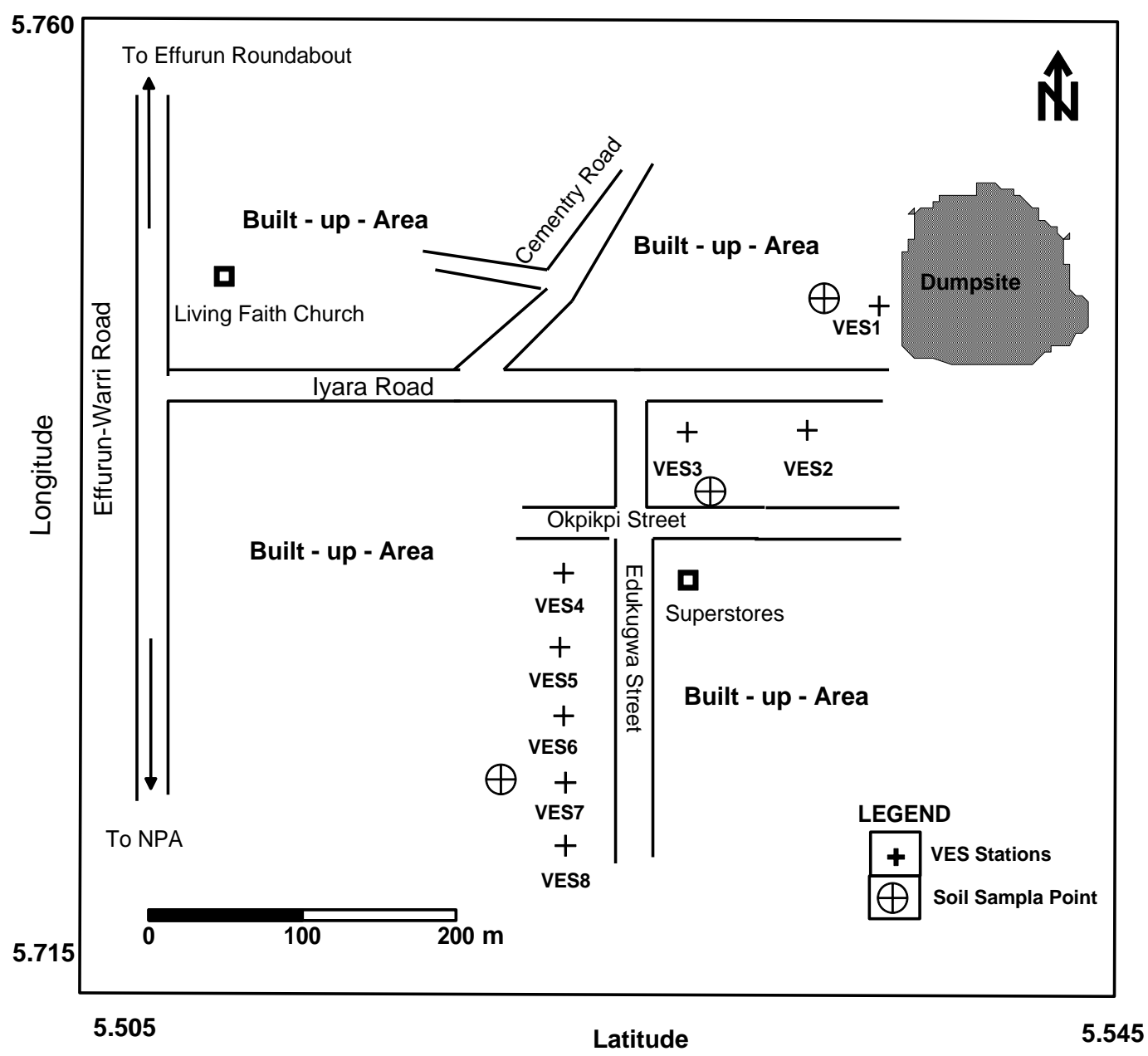

Figure 2. Data acquisition map of the study area

\subsection{Contamination/pollution Index (C/PI)}

The C/PI provides significant information on measured concentration of metals with regards to the intrinsic soil properties and their relationship to the maximum allowable limits for the metals $[12,13]$. This index was computed as a ratio of the measured concentration to the reference value [14].

$$
C / P \text { Index }=\frac{\text { Concentration of metal in soil }}{\text { References value }}
$$

In this study, the reference value of the maximum allowable levels of metals in soil from the Department of Petroleum Resources of Nigeria [15] was employed. C/P index value defines the pollution and contamination range when the ratio is greater or less than unity (1) respectively. The effect of more than one metal on organisms can be significant due to metallic interaction and this effect can be synergic, additive, or antagonistic. Therefore, multiple pollution index (MPI) was employed and was derived from the summation of the $\mathrm{C} / \mathrm{PI}$ values for individual metals greater than 1 . The $\mathrm{C} / \mathrm{P}$ and MP indices values were interpreted according to the scheme, $<0.1=$ very slight contamination; $0.10-0.25=$ slight contamination; $0.26-0.5=$ moderate contamination; 0.51 $0.75=$ severe contamination; $0.76-1.00=$ very severe contamination; $1.1-2.0=$ slight pollution; $2.1-4.0=$ moderate pollution; $4.1-8.0=$ severe pollution; $8.1-16.0=$ very severe pollution; $>16.0=$ excessive pollution .

\subsection{Quantification of Enrichment Factor (EF)}

The Enrichment Factor (EF) in metals are indicators used to evaluate the occurrence and concentration of anthropogenic contaminant deposition on surface soil. This factor, also called Geoaccumulation Index was calculated by normalizing the concentration of one metal in the topsoil with respect to the concentration of a reference element that are usually stable in the soil. Typical reference elements used in many research works are $\mathrm{Al}, \mathrm{Fe}, \mathrm{Mn}$ and $\mathrm{Rb}$. The enrichment factor was computed using the expression in Eq. (3) [16].

$$
\mathrm{EF}=\frac{\left.\mathrm{C}_{\mathrm{n}} \text { (sample }\right) / \mathrm{C}_{\mathrm{n}}(\text { reference })}{\left.\left.\mathrm{B}_{\mathrm{n}} \text { (test elements }\right) / \mathrm{B}_{\mathrm{n}} \text { (references }\right)}
$$

where,

$C_{n}($ sample $)=$ Concentration of the test elements in the sample.

$C_{n}($ reference $)=$ Concentration of the reference element in the sample.

$B_{n}($ test elements $)=$ Background concentration of test element in crustal rock.

$B_{n}$ (references $)=$ Background concentration of the reference element in crustal rocks.

Iron, was chosen as the reference element for this study being the most abundant element in the earth crust. The 
crustal abundant values for the respective metals according to Turekian and Wedepohl [17] were used for the calculation of the enrichment factors (Table 3) and the five contamination categories were identified $[18,19]$ and these include $\mathrm{EF}<2$ = deficiency to minimal enrichment, $\mathrm{EF}=2$ $5=$ moderate enrichment, $\mathrm{EF}=5-20=$ significant enrichment, $\mathrm{EF}=20-40=$ very high enrichment and $\mathrm{EF}>$ $40=$ extremely high enrichment [20].

\subsection{Ecological risk assessment}

This is a process that determines the possible occurrence of negative ecological effect that may arise due to exposure to one or more stressors. The index has been used for ecological risk evaluation of metals in sediments, soil and dust [21], and can be determined by the expression in Eq. (4).

$$
\mathrm{RI}=\sum \mathrm{E}_{\mathrm{r}}
$$

where, $\mathrm{E}_{\mathrm{r}}=\mathrm{T}_{\mathrm{r}} \mathrm{XCF}$ and $\mathrm{CF}=\mathrm{C}_{\mathrm{s}} / \mathrm{C}_{\mathrm{n}}$.

$\mathrm{CF}$ is the contamination factor and is a ratio of metal concentration in the sample (Cs) and that of the background $(\mathrm{Cn})$. Also, crustal abundance values of the respective metals were used as the background concentrations [17]. The Er, Tr and RI are the ecological risk, toxic response factor of each metal and that of multiple metal respectively. The toxic response factors for $\mathrm{Cd}, \mathrm{Cu}, \mathrm{Pb}, \mathrm{Cr}$ and $\mathrm{Zn}$ were $30,5,5,2$ and 1, respectively [22]. Based on their values, the Er and RI have been categorized into five and four categories respectively. These classifications are ER value $<40$ denotes low potential ecological risk, $\geq 40<80$ is moderate potential ecological risk, $\geq 80<160$ is considerable potential ecological risk, $\geq 160<320$ is high potential ecological risk and $\geq 320$ is very high potential ecological risk. Also RI value $<150$ indicates low ecological risk, $\geq 150<300$ is moderate ecological risk, $\geq 300<600$ is high ecological risk and $\geq 600$ is very high ecological risk [22].

\section{RESULTS AND DISCUSSION}

\subsection{Geophysical data interpretation}

A total number of eight VES stations were occupied in the study area and the field results showing current electrode separation, potential electrode separation, and the apparent resistivity measurements are presented in Table 1 . The apparent resistivity values obtained from the geoelectric survey were plotted on a log-log graph against the corresponding current electrode separation. The partial curve matching and subsequent computer iteration of the field data produced sounding curves (Figure 3) that mirror the geoelectric and lithologic subsurface layering showing formation resistivity, thicknesses and depths (Table 2).

From the sounding curves, three to four geoelectric layers were identified and they include the lateritic topsoils, clay, fine sand, and the medium-grained sand. The geoelectric section (Figure 4) shows that the first layer has resistivity value that ranges from 10.2 to $164.5 \Omega \mathrm{m}$. The thickness of this layer ranges from $0.6 \mathrm{~m}$ to $2.0 \mathrm{~m}$. This layer is composed of clayey topsoil. The second layer has resistivity value that ranges from 10.3 to $135.5 \Omega \mathrm{m}$. The thickness of this layer ranges from $0.5 \mathrm{~m}$ to $8.8 \mathrm{~m}$. This layer is composed of clayey sand. The third layer which is composed of fine-grain sand has resistivity and thickness values that range from 11.0 to $668.8 \Omega \mathrm{m}$ and $2.8 \mathrm{~m}$ to $8.9 \mathrm{~m}$ respectively. The fourth layer is composed of medium grain sand and has resistivity value that ranges from 36.0 to $740.8 \Omega \mathrm{m}$. The thickness of this layer is infinite as the current flow was terminated as this layer. Significantly, comparing the geoelectric section with a borehole $\log$ in the area indicate that the fine to medium grain sand of the third and fourth layers mainly constitute the aquifer with a depth ranging from 4.8-11 m.

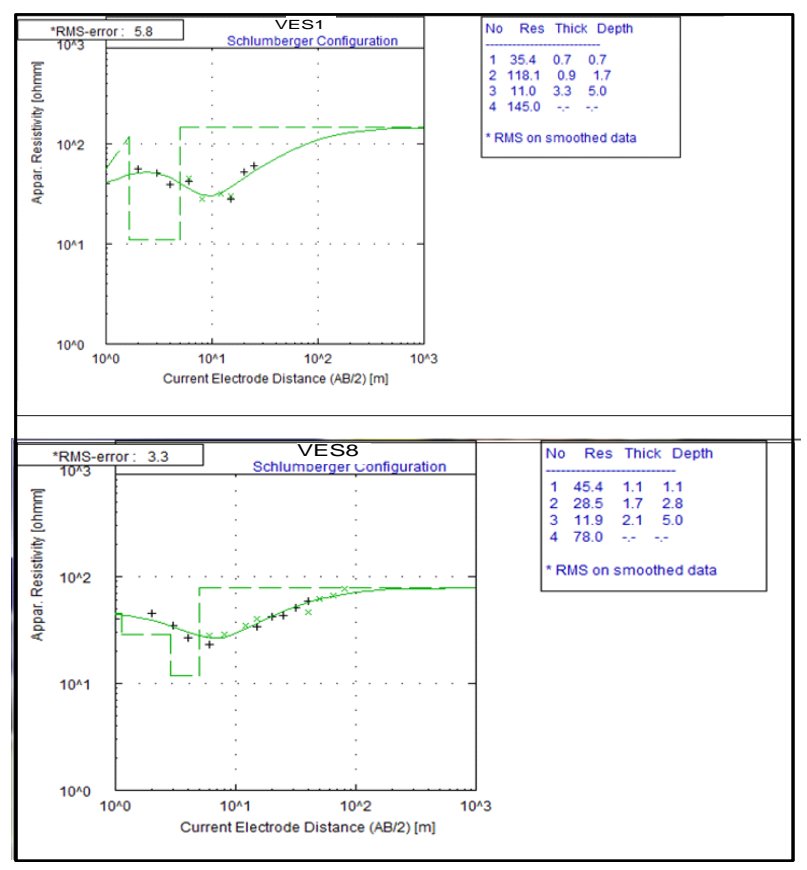

Figure 3. Typical sounding curves in the study area

Table 1. VES field data

\begin{tabular}{|c|c|c|c|c|c|c|c|c|c|}
\hline \multirow{2}{*}{$\begin{array}{l}\text { Current Electrode Separation } \\
\qquad \mathrm{AB} / 2(\mathrm{~m})\end{array}$} & \multirow{2}{*}{$\begin{array}{l}\text { Potential Electrode Separation } \\
\text { MN/2 (m) }\end{array}$} & \multicolumn{8}{|c|}{ Apparent Resistivity, $\rho(\Omega \mathrm{m})$} \\
\hline & & VES 1 & VES 2 & VES 3 & VES 4 & VES 5 & VES 6 & VES 7 & VES 8 \\
\hline 1 & 0.5 & 40 & 169 & 18 & 4 & 44 & 71 & 14 & 40 \\
\hline 2 & 0.5 & 56 & 233 & 15 & 27 & 30 & 81 & 26 & 45 \\
\hline 3 & 0.5 & 51 & 181 & 15 & 30 & 27 & 60 & 28 & 35 \\
\hline 4 & 0.5 & 39 & 114 & 15 & 22 & 24 & 42 & 29 & 37 \\
\hline 6 & 0.5 & 42 & 49 & 13 & 18 & 19 & 27 & 30 & 23 \\
\hline 6 & 1.0 & 45 & 60 & 30 & 15 & 19 & 25 & 34 & 28 \\
\hline 8 & 1.0 & 28 & 28 & 25 & 17 & 15 & 23 & 31 & 29 \\
\hline 12 & 1.0 & 32 & 31 & 28 & 20 & 14 & 23 & 35 & 35 \\
\hline 15 & 1.0 & 30 & 37 & 37 & 19 & 16 & 27 & 38 & 40 \\
\hline 15 & 2.0 & 28 & 94 & 24 & 31 & 18 & 33 & 18 & 34 \\
\hline 20 & 2.0 & 52 & 71 & 27 & 15 & 23 & 31 & 36 & 42 \\
\hline
\end{tabular}




\begin{tabular}{|c|c|c|c|c|c|c|c|c|c|}
\hline 25 & 2.0 & 60 & 11 & 35 & 197 & 21 & 40 & 44 & 43 \\
\hline 32 & 2.0 & & 55 & 49 & 25 & 34 & 54 & 48 & 51 \\
\hline 40 & 2.0 & & 114 & 89 & 78 & 45 & 72 & 57 & 59 \\
\hline 40 & 5.0 & & 16 & 134 & 102 & 65 & 67 & 82 & 46 \\
\hline 50 & 5.0 & & 25 & 64 & 40 & 96 & 110 & 109 & 62 \\
\hline 65 & 5.0 & & 100 & & 36 & 61 & 25 & 82 & 67 \\
\hline 80 & 5.0 & & & & 18 & 75 & 183 & 89 & 76 \\
\hline 100 & 5.0 & & & & 147 & 101 & 227 & 123 & \\
\hline 100 & 10.0 & & & & 87 & 67 & 142 & 69 & \\
\hline 120 & 10.0 & & & & 250 & 112 & 186 & & \\
\hline 150 & 10.0 & & & & & 160 & & & \\
\hline
\end{tabular}

Table 2. Geoelectric parameters and lithologic delineation of study area

\begin{tabular}{|c|c|c|c|c|c|}
\hline VES Station & Layers & Resistivity $(\Omega \mathrm{m})$ & Thickness (m) & Depth (m) & Lithology \\
\hline \multirow{4}{*}{ VES 1} & 1 & 35.4 & 0.7 & 0.7 & Clayey topsoil \\
\hline & 2 & 118.1 & 0.9 & 1.7 & Clayey Sand \\
\hline & 3 & 11.0 & 3.3 & 5.0 & Fine sand \\
\hline & 4 & 145.0 &.---- &.---- & Medium grain sand \\
\hline \multirow{3}{*}{ VES 2} & 1 & 164.5 & 2.0 & 2.0 & Clayey topsoil \\
\hline & 2 & 16.1 & 2.8 & 4.8 & Fine sand \\
\hline & 3 & 71.6 &.---- & --.-- & Medium grain sand \\
\hline \multirow{3}{*}{ VES 3} & 1 & 16.9 & 0.6 & 0.6 & Clayey topsoil \\
\hline & 2 & 15.9 & 4.9 & 5.5 & Clayey sand \\
\hline & 3 & 78.0 & --.-- &.---- & Medium grain sand \\
\hline \multirow{4}{*}{ VES 4} & 1 & 31.6 & 1.3 & 1.3 & Clayey topsoil \\
\hline & 2 & 10.8 & 2.9 & 4.3 & Clayey sand \\
\hline & 3 & 114.7 & 4.8 & 9.0 & Fine sand \\
\hline & 4 & 36.0 & $\ldots \ldots$ & $\ldots \ldots$ & Medium grain sand \\
\hline \multirow{3}{*}{ VES 5} & 1 & 38.4 & 1.9 & 1.9 & Clayey topsoil \\
\hline & 2 & 10.3 & 8.8 & 10.7 & Fine sand \\
\hline & 3 & 668.8 & --.-- &.---- & Medium grain sand \\
\hline \multirow{4}{*}{ VES 6} & 1 & 73.2 & 0.7 & 0.7 & Clayey topsoil \\
\hline & 2 & 108.1 & 0.9 & 1.6 & Clayey sand \\
\hline & 3 & 14.5 & 8.2 & 9.7 & Fine sand \\
\hline & 4 & 740.8 & --.-- &.---- & Medium grain sand \\
\hline \multirow{4}{*}{ VES 7} & 1 & 10.2 & 0.6 & 0.6 & Clayey topsoil \\
\hline & 2 & 135.5 & 0.5 & 1.1 & Fine sand \\
\hline & 3 & 22.9 & 8.9 & 10.0 & Clayey sand \\
\hline & 4 & 177.8 &.--- &.---- & Medium grain sand \\
\hline \multirow{4}{*}{ VES 8} & 1 & 45.4 & 1.1 & 1.1 & Clayey topsoil \\
\hline & 2 & 28.5 & 1.7 & 2.8 & Clayey sand \\
\hline & 3 & 11.9 & 2.1 & 5.0 & Fine sand \\
\hline & 4 & 78.0 &.---- &.---- & Medium grain sand \\
\hline
\end{tabular}
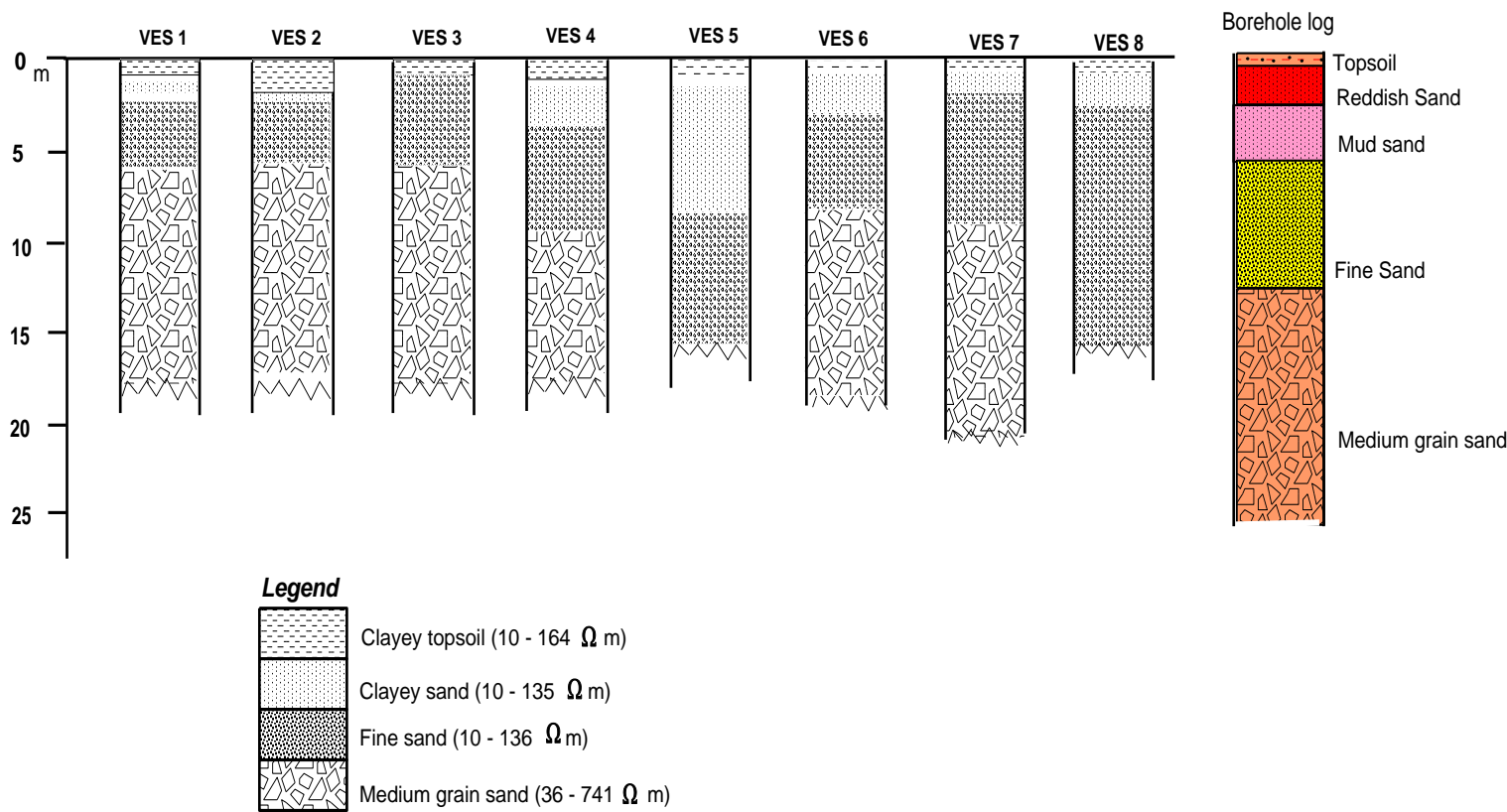

Figure 4. Geoelectric section of study area 


\subsection{Heavy metal analysis of samples}

The soil samples were collected at three locations around VES 1, 3 and 7 and were labeled SAMPLE I, SAMPLE II, and SAMPLE III respectively. The concentration of the soil samples in $\mathrm{mgkg}^{-1}$ are given in Table 3 . The concentration comparison is shown in Figure 5. Fe has the highest concentration and manganese the least concentration.

Table 3. Total metal concentration $(\mathrm{mg} / \mathrm{kg})$ in soil samples

\begin{tabular}{cccc}
\hline METAL & SAMPLE I & SAMPLE II & SAMPLE III \\
\hline $\mathrm{Cu}$ & 318 & 257 & 310 \\
$\mathrm{Ni}$ & 365 & 405 & 377 \\
$\mathrm{~Pb}$ & 196 & $\mathrm{Nd}$ & 160 \\
$\mathrm{Zn}$ & 1516 & 754 & 706 \\
$\mathrm{Co}$ & 403 & 227 & 209 \\
$\mathrm{Mn}$ & 135 & $\mathrm{Nd}$ & $\mathrm{Nd}$ \\
$\mathrm{Fe}$ & 34484 & 21150 & 14383 \\
\hline
\end{tabular}

where, 'Nd' means not detected.

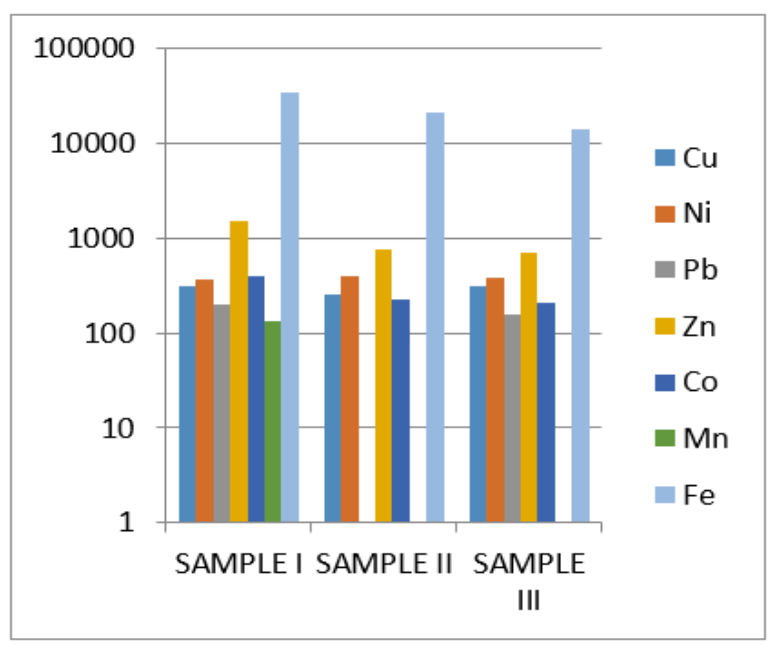

Figure 5. Concentration metals (in $\mathrm{mg} / \mathrm{kg}$ ) from soil samples

\subsubsection{Results of chemical analysis of samples}

The results from the atomic absorption spectrometry showing the amount of each metal in $\mathrm{mg} / \mathrm{kg}$ is shown in Table 3. The metals analyzed were $\mathrm{Cu}, \mathrm{Ni}, \mathrm{Pb}, \mathrm{Zn}, \mathrm{Co}, \mathrm{Mn}$, and $\mathrm{Fe}$. The table shows the concentration of the metals in soil samples collected at $1 \mathrm{~m}$ beneath the ground around the different VES locations (VES 1, 3, and 7). Majorly, municipal solid waste dominates the dumpsite, and it is for this reason that the selected metals were considered as they are associated with municipal solid waste. In Figure 4, at VES 1 (i.e. SAMPLE I), Fe has the highest concentration of $34484 \mathrm{mg} / \mathrm{kg}$ compared to the other metals. This is the same trend observed at the other locations (for SAMPLES II and III). However, it was seen that there is a minimal reduction in the concentration of each metal from SAMPLE I to SAMPLE II (that is, concentration of metals in the soil samples are in the order SAMPLE I > SAMPLE II > III) except for Ni with concentration in SAMPLE I lower than that in the other two samples. This implies that the concentration of metals in VES 1 location is higher than the concentration in VES 3 and VES 7 locations. This higher concentration value in SAMPLE I (VES 1 station) might be due to the fact that VES 1 is the actual dumpsite location while VES 3 and VES 7 are at some few distances from the dumpsite (Figure 2). The concentration of metals in the investigated soil decreased with respect to the distance from the dumpsite. The concentration of metals measured in soil within the dumpsite was higher than the concentration observed at other locations away from the dumpsite. Also, the concentrations of metals in the studied soils were compared with crustal abundance values, national and international guidelines for metals in soil (Table 3). The values were below their respective crustal abundance. The concentration of $\mathrm{Cu}$ was $318 \mathrm{mg} / \mathrm{kg}$ within the dumpsite and ranged from $257-310 \mathrm{mg} / \mathrm{kg}$ at other locations. Lower concentration of copper was observed in SAMPLE II (VES 3 location) compared to that in SAMPLE I (VES 1 location) and SAMPLE III (VES 7). The concentration of $\mathrm{Cu}$ found in these samples were higher than the WHO and DPR of Nigeria permissible limit of $36 \mathrm{mg} / \mathrm{kg}$. The concentration of copper found in these samples was lower than the WHO and DPR target values. Also, the concentration of Nickel was 365 $\mathrm{mg} / \mathrm{kg}$ around the dumpsite and ranged from $377-405 \mathrm{mg} / \mathrm{kg}$ at other locations distance away from the dumpsite which exceeded the WHO and DPR permissible limit of $36 \mathrm{mg} / \mathrm{kg}$ $[15,23]$. The concentration of $\mathrm{Ni}$ observed in the soil around the dumpsite was lower than the concentration of $\mathrm{Ni}$ found in soils in VES locations 3 and 7. The concentration of $\mathrm{Pb}$ in these soil profiles were $196 \mathrm{mg} / \mathrm{kg}$ in samples from the dumpsite location and $160 \mathrm{mg} / \mathrm{kg}$ at VES 7 location, with the highest concentration observed around VES 1 . These values are higher than the maximum allowable concentration of $\mathrm{Pb}$ in the soil which is $85 \mathrm{mg} / \mathrm{kg}[15,23]$. The concentration of $\mathrm{Zn}$ in all the samples varied from $706-1516 \mathrm{mg} / \mathrm{kg}$ with the highest concentration of $1516 \mathrm{mg} / \mathrm{kg}$ in SAMPLE I (VES 1). These values are higher than the permissible limit for $\mathrm{Zn}$ in soil which is $140 \mathrm{mg} / \mathrm{kg}$. Also, the concentration of cobalt is $403 \mathrm{mg} / \mathrm{kg}$ for SAMPLE I, $227 \mathrm{mg} / \mathrm{kg}$ for SAMPLE II and $209 \mathrm{mg} / \mathrm{kg}$ for SAMPLE III, with the highest concentration around VES location 1 like other metals. However, Co concentrations in the range of $3.55-58.9 \mathrm{mg} / \mathrm{kg}$ have been reported in the urban soils of different cities in Nigeria [24]. The concentration of $\mathrm{Mn}$ is $135 \mathrm{mg} / \mathrm{kg}$ in SAMPLE I and not detected in SAMPLE II and III. This value is below the crustal abundance value $(950 \mathrm{mg} / \mathrm{kg})$ and the permissible limit $(450 \mathrm{mg} / \mathrm{kg})$. In the soil profile, Fe has a concentration ranged from $14383 \mathrm{mg} / \mathrm{kg}$ to $34484 \mathrm{mg} / \mathrm{kg}$ with the highest concentration observed in SAMPLE I (VES 1 location). The concentrations of $\mathrm{Fe}$ observed in these soil profiles were below the crustal abundance value of $\mathrm{Fe}$ of $45000 \mathrm{mg} / \mathrm{kg}$.

\subsection{Quantification of soil pollution}

To determine the extent of contamination of the soils around the dumpsites, the data obtained were compared with those from the control sample point, which is taken to be the background (uncontaminated) values. Various quantitative indices have been engaged to assess the impact of human activities on the concentration of toxic trace metals in soils [25]. In this study, two pollution indices were employed single indices and integrated indices. These include contamination/pollution index and enrichment factor and; non-carcinogenic hazard index.

\subsubsection{Contamination/pollution index (C/PI)}

The contamination/pollution $(\mathrm{C} / \mathrm{P})$ index was calculated as the ratio between metallic concentration effectively measured by chemical analysis to the reference value. The 
contamination/pollution index for the soil samples from study area is shown in Table 4 . Table 4 gives the values of contamination/pollution index for the heavy metals at respective areas. Comparing the results with the categories of contamination/pollution index, it is concluded that in all the three locations studied, there is very high pollution of $\mathrm{Cu}$ at VES 1 and 7 locations $(8.1 \leq \mathrm{C} / \mathrm{PI} \geq 16)$ and severe contamination at VES 3 location $(4.1 \leq \mathrm{C} / \mathrm{PI} \geq 8.0)$. For $\mathrm{Ni}$, the results show high pollution at the three locations $(8.1 \leq$ $\mathrm{C} / \mathrm{PI} \geq 16$ ). The table also shows an index ranging from severe pollution to very severe pollution for $\mathrm{Zn}$ with the highest pollution index at VES 1 and a range of slight contamination to moderate pollution for $\mathrm{Pb}$. Also, for all three samples, $\mathrm{Co}$ has the highest metal contamination on the basis of contamination/pollution index while Mn has the least.

Table 4. Contamination/Pollution index for soil samples

\begin{tabular}{ccccccccc}
\hline $\begin{array}{c}\text { SAMPL } \\
\text { E }\end{array}$ & $\mathrm{Cu}$ & $\mathrm{Ni}$ & $\mathrm{Pb}$ & $\mathrm{Zn}$ & $\mathrm{Co}$ & $\mathrm{Mn}$ & $\mathrm{Fe}$ & $\mathrm{MPI}$ \\
\hline I & 8.83 & 10.43 & 2.31 & 10.83 & 20.15 & 0.31 & 6.9 & 59.45 \\
II & 7.14 & 11.57 & & 5.39 & 11.35 & & 4.23 & 39.68 \\
III & 8.6 & 10.77 & 1.88 & 5.04 & 10.45 & & 2.88 & 39.62 \\
\hline
\end{tabular}

The multiple pollution index values for these sites ranged from approximately 40-60 with a significant contribution of all the metals except Mn which has a pollution index of 0.31 . The MPI values decreased with increasing distance from the dumpsite, which establishes that the extent of pollution around the dumpsite are more than at some distance away ( $\geq 100 \mathrm{~m}$ away from the dumpsite). The magnitude of pollution by these metals followed the order I $>$ II $>$ III.

\subsubsection{Enrichment Factor (EF)}

Table 5 shows the estimated Enrichment Factor (EF) for metals in soils around the study area. This is a function of the presence of anthropogenic contaminants in the soil. Apart from $\mathrm{Mn}$ in SAMPLE I and Fe (reference sample) in the three samples, other metals in the three samples have enrichment factor $>1$. The enrichment factor decreased in the order $\mathrm{Zn}>\mathrm{Co}>\mathrm{Pb}>\mathrm{Cu}>\mathrm{Ni}>\mathrm{Fe}>\mathrm{Mn}$. In this study, the soil collected at VES 1 location had lower EF values than those collected at VES 3 and 7, away from the dumpsite location. Soils within the dumpsite were enriched with metals than those collected at a distance away. From contamination categorization based on the enrichment factor values, the enrichment factors at the three locations (except $\mathrm{Mn}$ in SAMPLE I) fall within the range of moderate enrichment to very high enrichment.

Table 5. Enrichment factor (EF) of soils

\begin{tabular}{cccc}
\hline METALS & SAMPLE I & SAMPLE II & SAMPLE III \\
\hline $\mathrm{Cu}$ & 7.56 & 9.96 & 17.67 \\
$\mathrm{Ni}$ & 5.42 & 9.81 & 13.43 \\
$\mathrm{~Pb}$ & 16.65 & $\mathrm{ND}$ & 32.58 \\
$\mathrm{Zn}$ & 24.03 & 19.49 & 26.83 \\
$\mathrm{Co}$ & 23.96 & 22 & 29.79 \\
$\mathrm{Mn}$ & 0.17 & $\mathrm{ND}$ & $\mathrm{ND}$ \\
$\mathrm{Fe}$ & 1 & 1 & 1 \\
\hline \multicolumn{4}{c}{$\mathrm{ND}=$ Not Detected }
\end{tabular}

\subsubsection{Non-carcinogenic hazard}

The non-carcinogenic risk evaluated based on the total metal concentration of the children and adult scenarios is displayed in Table 6. The non-carcinogenic hazards of the different exposure path way indicated that $H Q_{\text {ing }} \gg$ $H Q_{\text {dermal }} \gg H Q_{\text {inh }}$ for the children which is possible due to hand to mouth habit of children. Cumulatively, the $H I$ for the children was 2.46 within the dumpsite and 1.14-1.6 at $\geq 100$ $\mathrm{m}$ distance away from the dumpsite. The $H I$ of metals for adult case was 1.18 for VES 1 location and ranged from 0.61 0.62 in the other two locations. The non-carcinogenic risk of metals in soil was higher at the dumpsite than away from it.

Table 6. Non-carcinogenic risk in children and adults

\begin{tabular}{clllllllll}
\hline & \multicolumn{4}{c}{ CHILD } & \multicolumn{4}{c}{ ADULT } \\
\hline Sampl & $\mathrm{HQ}_{\text {ing }}$ & $\mathrm{HQ}_{\text {inh }}$ & $\mathrm{HQ}_{\text {derm } \varepsilon}$ & $\mathrm{HI}$ & $\mathrm{HQ}_{\text {ing }}$ & $\mathrm{HQ}_{\text {inh }}$ & $\mathrm{HQ}_{\text {derm } \varepsilon}$ & $\mathrm{HI}$ \\
$\mathrm{e}$ & & 0 & 0.18 & 2.46 & 1.02 & 0 & 0.19 & 1.18 \\
$\mathrm{I}$ & 2.36 & 0 & 0.11 & 1.60 & 0.57 & 0 & 0.11 & 0.61 \\
$\mathrm{II}$ & 1.49 & 0 & 0.11 & 0.14 & 0.64 & 0 & 0.10 & 0.62 \\
$\mathrm{III}$ & 1.04 & 0 & 0.1 & 1.14 &
\end{tabular}

\subsection{Effect of the metals on the soils and groundwater of study area}

From geoelectric section and lithologic delineation (Table 2 and Figure 3), and the results of the geochemical analysis, an attempt to relate the depth to water table and resistivity of each VES locations where samples were collected to the metal concentration at the locations was made.

At VES 1, the aquifer is located at the third layer with a resistivity of $11 \Omega \mathrm{m}$ and a depth of $5.0 \mathrm{~m}$. The results from the chemical analysis showed high metal concentration at this location and thus concluded that the low resistivity of this aquifer is as a result of the high metal concentration. This implies that groundwater from this location is not suitable for drinking and other domestic purposes.

At VES 3, the aquifer is located at the third layer with resistivity $78.0 \Omega \mathrm{m}$ (higher than the aquifer resistivity at VES location 1) which extends to unknown depth. The soil sample was collected from the first layer with resistivity of $16.9 \Omega \mathrm{m}$ and depth of $2.0 \mathrm{~m}$. The results from the chemical analysis showed high metal concentration at this location, though lower than values obtained at VES 1 . Therefore, it can be concluded that the low resistivity of this aquifer is a result of the high metallic concentration in this location. It can also be inferred that the results from the geochemical analysis are in line with the VES results since the resistivity of the aquifer in VES 3 is higher than that obtained in VES 1 . It can be concluded that groundwater from this location (although not suitable for domestic activities) is of lower metallic concentration than groundwater at VES 1 by the dumpsite. At VES 7, the aquifer is located at the third layer also with resistivity $22.9 \Omega \mathrm{m}$ (higher than the aquifer resistivity at VES location 1 but lower than that obtained in VES 3 location) which extends to a depth of $10.0 \mathrm{~m}$. The soil sample collected at this location was collected from the second layer with resistivity of $135.5 \Omega \mathrm{m}$ and depth of $1.1 \mathrm{~m}$. The results from the chemical analysis showed high metallic concentration at this location lower than that obtained in VES 1 but higher than that in VES 3. These results are in line with the geoelectrical survey since the resistivity of the aquifer in VES 7 is higher than that obtained in VES 1 but lower than that obtained in VES 3. It can be concluded that groundwater quality in terms of heavy metal concentration is highest around the dumpsite area of the range VES 3>VES 7>VES 1. 


\section{CONCLUSION}

The experimental data revealed that the concentrations of the examined metals varied widely among the different VES locations with greater concentration around the dumpsite. The concentrations of metals found in these sites were above the maximum allowable levels in soils as specified by WHO and DPR except for $\mathrm{Pb}$ whose concentration was unknown in sample III and Mn with $135 \mathrm{mg} / \mathrm{kg}$ in VES 1 and undetected in VES 3 and 7. Also, the concentrations of these metals were higher in SAMPLE I than the two other samples (SAMPLES II and III) collected at about $100 \mathrm{~m}$ away from the dumpsite. The multiple pollution indexes established that the soil is within "slight contamination" to "very high pollution". This study indicates that dumpsites are a possible source of elevated concentrations of metal species.

\section{ACKNOWLEDGEMENT}

The authors appreciate the Department of Physics, Delta State University, Abraka for the release of the Terrameter used for the data collection. The Central Laboratory, University of Ibadan Nigeria is also appreciated for the soil analysis.

\section{REFERENCES}

[1] Ali, H., Khan, E., Ilahi, I. (2019) Environmental chemistry and ecotoxicology of hazardous heavy metals: Environmental persistence, toxicity, and bioaccumulation. Journal of Chemistry, 2019: 6730305. https://doi.org/10.1155/2019/6730305

[2] Emoyan, O.O., Peretiemo-Clarke, B.O., Tesi G.O., Adjerese, W., Ohwo, E. (2021). Occurrence, origin and risk assessment of heavy metals measured in petroleum tank-farm impacted soils. Soil and Sediment Contamination: An International Journal, 30(4): 384408. https://doi.org/10.1080/15320383.2020.1854677

[3] Ergin, M., Saydam, C., Basturk, O., Erdem, E., Yoruk, R. (1991). Heavy metal concentrations in surface sediments from the two coastal inlets (Golden Horn Estuary and İzmit Bay) of the northeastern Sea of Marmara. Chemical Geology-Science, 91(3): 269-285. https://doi.org/10.1016/0009-2541(91)90004-B

[4] Loko, M.H., Acworth, I., Dahlin, T. (2003). A comparison of smooth and blocky inversion methods in 2D electrical imaging surveys. Exploration Geophysics, 34(3): 182-187. https://doi.org/10.1071/EG03182

[5] Jegede, S.I., Ujuanbi, O., Iserhien-Emekeme, R.E., Iyayi, S.A. (2012). Detection of trace metal contamination in a vegetable grown soil using electrical resistivity tomography technique. IRCAB Journal of Natural and Applied Sciences, 2(1): 69-80.

[6] Ameloko, A.A., Ayolabi, E.A. (2018). Geophysical assessment for vertical leachate migration profile and physicochemical study of groundwater around the Olusosun dumpsite Lagos, south-west Nigeria. Applied Water Science, 8: 142. https://doi.org/10.1007/s13201018-0775-X

[7] Frid, V., Liskevich, G., Doudkinski, D., Korostishevsky, N. (2008). Evaluation of landfill disposal boundary by means of electrical resistivity imaging. Environmental
Geology,

53:

https://doi.org/10.1007/s00254-007-0761-3

[8] Abdullahi, A.S., Funtua, I.I., Dewu, B.L.M., Alagbe, S.A. (2010). Study of the suitability of groundwater for household and irrigation purposes in parts of Adamawa State, Northeastern Nigeria. International Archive of Applied Science and Technology, 1(2): 48-56.

[9] Porsani, J.L., Filho, W.M., Elisa, V.R., Shimeles, F., Dourado, J.C, Moura, H.P. (2004). The use of GPR and VES in delineating a contamination plume in a landfill site: A case study in SE Brazil. Journal of Applied Geophysics, $\quad 55(3)$ : https://doi.org/10.1016/j.jappgeo.2003.11.001

[10] Loke, M.H. (2004). Practical Guide for 2D and 3D Electrical Imagine Surveys (From the internet), 1-136. https://sites.ualberta.ca/ unsworth/UAclasses/223/loke_course_notes.pdf.

[11] Wightman, W.E., Jalinoos, F., Sirles, P., Hanna, K. (2003). Application of Geophysical Methods to Highway Related Problems. Federal Highway Administration, Central Federal Lands Highway Division, Lakewood, CO, Publication No. FHWA-IF04-021. http://www.cflhd.gov/resources/agm/.

[12] Iwegbue, C.M.A., Nwajei, G.E., Ogala, J.E., Overah, C.L. (2010). Determination of trace metal concentrations in soil profiles of municipal waste dumps in Nigeria. Environmental Geochemistry and Health, 32: 415-430. https://doi.org/10.1007/s10653010-9285-y

[13] Iwegbue, C.M.A., Nwajei, G.E., Eguavoen, O.I. (2012). Impact of land use patterns on chemical properties of trace elements in soils of rural, semi-urban and urban zones of the Niger Delta, Nigeria. Soil Sediment Contamination, 21(1): 19-30. https://doi.org/10.1080/15320383.2012.636772

[14] Lacatusu, R. (2000) Appraising levels of soil contamination and pollution with heavy metals. In: Heinike H.J., Eckrelman W., Thomasson A.J., Jones R.J.A., Montanarella L., Buckley B. (eds) Land information system for planning the sustainable use of land resources. European soil bureau. Research Report no 4. Office for Official Publication of the European Communities, Luxembourg, pp. 393-402.

[15] Department of Petroleum Resources (DPR). (2002). Environmental guidelines and standards for the petroleum industries in Nigeria Department of Petroleum Resources, Ministry of Petroleum and Mineral Resources, Abuja-Nigeria.

[16] Reimann, C., De Caritat, P. (2000). Intrinsic flaws of element enrichment factor (EFs) in environmental geochemistry. Environmental Science and Technology 34: 5084-5091. https://doi.org/10.1021/es001339o

[17] Turekian, K.K., Wedepohl, K.H. (1961). Distribution of the elements in some major units of earth crust. Bulletin of the Geological Society of America, 72(2): 175-192. https://doi.org/10.1130/00167606(1961)72[175:DOTEIS]2.0.CO;2

[18] Sutherland, R.A. (2000). Bed sediment associated trace element in urban stream Oahu, Hawaii. Environmental Geology, 39: 361-627. https://doi.org/10.1007/s002540050473

[19] Loska, K., Wiechula, D. (2003). Application of principle components analysis for the estimation of source of heavy metal contamination in surface 
sediments from the Rybnik Reservoir. Chemosphere, 51: 723-733. $\quad$ https://doi.org/10.1016/S00456535(03)00187-5

[20] Manno, E., Varrica, D., Dongarra, G. (2006). Metal distribution in road dust samples collected in an urban area close to a petrochemical plant at Gela, Sicily. Atmospheric Environment, 40(30): 5929-5941. https://doi.org/10.1016/j.atmosenv.2006.05.020

[21] Saeedi, M., Li, L.Y., Salmanzadeh, M. (2012). Heavy metal and polycyclic aromatic hydrocarbons: Pollution and ecological risk assessment in street dust of Tehran. Journal of Hazardous Materials, 227-228: 9-17. https://doi.org/10.1016/j.jhazmat.2012.04.047

[22] Hakanson, L. (1980). An ecological risk index for aquatic pollution control, a sedimentological approach.
Water Resources, 14(8): 975-1001. https://doi.org/10.1016/0043-1354(80):90143-8

[23] WHO. (1996). Permissible limit of Heavy metals in soil and plants (Geneva: World Health Organization), Switzerland.

[24] Eze, V.C., Onyilide D.M. (2015). Microbiological and physiochemical characteristics of soil receiving cassava effluents in Elele, Rivers state, Nigeria. Journal of Applied and Environmental Microbiology, 3(1): 20-24.

[25] Olorunfemi, A.O., Alao-Daniel, A.B., Adesiyan, T.A., Onah, C.E. (2020). Geochemical assessment of heavy metal impact on soil around Ewu-Elepe Dumpsite, Lagos State, Nigeria. Ife Journal of Science, 22(3): 119138. https://doi.org/10.4314/ijs.v22i3.10 